\title{
Sexual Dimorphism in the Permanent Maxillary First Molar Teeth in the Rajasthan Population
}

\author{
Suresh Sharma ${ }^{1}$, Shantnu Sharma²
}

\begin{abstract}
Introduction: Sex estimation in forensic science is an essential step for medicolegal purposes. Teeth are an excellent material for anthropological, odontological, genetic, and forensic investigations as they are known to resist a variety of ante-mortem and post-mortem insults. Sexual dimorphism is an indicator of gender differences that can be observed in several aspects of the human skeleton such as the pelvis, cranium, femur, humerus, canines, and other structures. Maxillary first molars are the first permanent teeth to erupt into the oral cavity at the mean age of 6-7 years and are less commonly impacted as compared to canines. The purpose of this study was to indicate whether sexual dimorphism also exists in the first maxillary molar of humans.

Aim: To determine the sexual dimorphism in the permanent maxillary first molar teeth using the mesiodistal and buccolingual crown width. Materials and methods: The present study was performed on 80 patients from the National Institute of Medical Sciences and Research, Jaipur. Mesiodistal and buccolingual width were measured on the basis of intraoral examination and plaster modal with the help of Vernier caliper. Sexual dimorphism (in percentage) was calculated from these measured parameters.

Results: The mean values of right and left mesiodistal width and buccolingual width were less for females than for males and the differences were statistically significant for buccolingual width but nonsignificant for mesiodistal width. The sexual dimorphism was slightly greater on the right side than the left side. Buccolingual width of right maxillary molar teeth shows maximum sexual dimorphism among all measurements (both intraoral $5.13 \%$ and cast $5.18 \%$ ).

Conclusion: This study signifies the possible role of morphometric study of canine teeth in estimation of gender and it can be used in forensic investigations where gender determination of skeletal remains is difficult.

Keywords: Buccolingual, Mesiodistal, Odontological, Sexual dimorphism.

Journal of Mahatma Gandhi University of Medical Sciences \& Technology (2020): 10.5005/jp-journals-10057-0119
\end{abstract}

\section{INTRODUCTION}

Every human being is born with an identity and has the right to die with an identity. Identity means the determination of the individuality of a person. ${ }^{1}$ Human identification is based on scientific principles mainly involving DNA analysis, fingerprints, and dental records. ${ }^{2,3}$ The DNA profile will provide accurate results but the measurements in anthropometric or odontometric studies used for sex determination are simple, reliable, inexpensive, and easy to measure.

Anatomical structures including pelvic girdle, skull, and dentition have been implicated time and again by the forensic anthropologists to conclude the gender and age of skeletal remains. Teeth measurements are effectively genuine tool in determination of gender and age particularly in cases where secondary sexual characteristics have either not developed or where certain body parts otherwise useful to make sure the gender and age were missing. ${ }^{4,5}$

Dentition being the hardest and chemically most stable tissue in the body is an excellent material in living and nonliving populations for anthropological, odontologic, genetic, and forensic investigations. ${ }^{6}$ These exhibit the least turnover of natural structure and are easily accessible for examination. Their durability in the face of fire and bacterial decomposition makes them of great importance for identification. Different features of teeth, including their detailed morphology, crown size, root lengths, etc., tend to vary between males and females. These variations can help a forensic scientist to identify the gender and age of the victims of mass disasters, since
${ }^{1}$ Department of Anatomy, National Institute of Medical Sciences and Research, Jaipur, Rajasthan, India

${ }^{2}$ Department of Orthodontics, National Institute of Medical Sciences Dental College, Jaipur, Rajasthan, India

Corresponding Author: Suresh Sharma, Department of Anatomy, National Institute of Medical Sciences and Research, Jaipur, Rajasthan, India, Phone: +91 9929683002, e-mail: suresh85anita@gmail.com

How to cite this article: Sharma S, Sharma S. Sexual Dimorphism in the Permanent Maxillary First Molar Teeth in the Rajasthan Population. J Mahatma Gandhi Univ Med Sci Tech 2020;5(1):4-8.

Source of support: Nil

Conflict of interest: None

the teeth are generally preserved even when the soft tissue and bones have been destroyed. ${ }^{7,8}$

The purpose of this study was to evaluate the existence of sexual dimorphism using both mesiodistal and buccolingual dimensions of maxillary first molars, as they are the first permanent teeth to erupt into the oral cavity at the mean age of 6-7 years and are less commonly impacted as compared to canines.

\section{Aims and Objectives}

The aim of the present study is to determine the sexual dimorphism in the permanent maxillary first molar teeth using the mesiodistal and buccolingual crown width. 


\section{Materials and Methods}

This study was conducted in the Department of Anatomy, National Institute of Medical Sciences and Research, Jaipur (Raj), India, on 80 subjects ( 40 male and 40 female), aged $20-40$ years. The subjects were selected based on the inclusion and exclusion criteria set forth for the study.

\section{Inclusion Criteria}

- Fully formed permanent maxillary first molar

- Caries, attrition, abrasion, and erosion free

- Intact contact area

\section{Exclusion Criteria}

- Missing first molar

- Any pathology or developmental anomaly

- Restorations and capping

- Malaligned teeth

Following informed consent, impressions of maxillary arch were made with irreversible hydrocolloid (alginate) material and casts poured immediately in type Il dental stone to minimize dimensional change. Buccolingual (BL) and mesiodistal (MD) crown diameters of maxillary first molars were measured using digital Vernier calipers (resolution $0.01 \mathrm{~mm}$ ) both intraoral and on study casts.

- Buccolingual diameter of the crown: This measurement is the greatest distance between buccal and lingual surfaces of crown, taken at right angles to the plane in which mesiodistal diameter is taken.

- Mesiodistal diameter of the crown: This measurement is the greatest mesiodistal dimension between the contact points of teeth on either side of the jaw.

Table 1: Mean \pm SD of right and left buccolingual width of intraoral and cast in females

\begin{tabular}{|c|c|c|c|c|}
\hline \multirow[b]{2}{*}{ Parameters } & \multicolumn{2}{|c|}{ Mean $\pm S D$} & \multirow[b]{2}{*}{$p$ value } & \multirow[b]{2}{*}{ Significance } \\
\hline & Right & Left & & \\
\hline Intraoral & $10.33 \pm 0.90$ & $10.15 \pm 0.91$ & 0.3765 & Nonsignificant \\
\hline Cast & $10.43 \pm 0.92$ & $10.25 \pm 0.89$ & 0.3765 & Nonsignificant \\
\hline
\end{tabular}

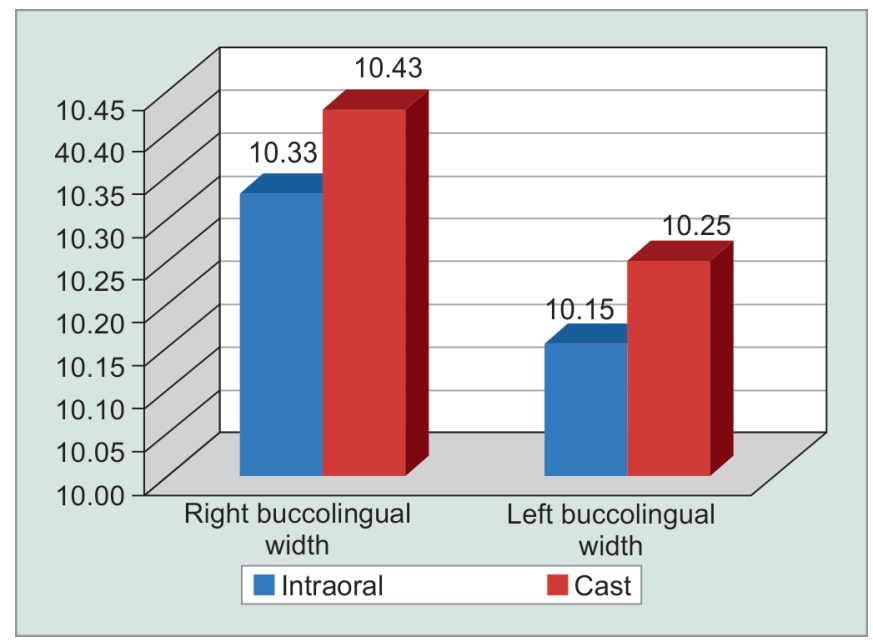

Fig. 1: Mean \pm SD of right and left buccolingual width of intraoral and cast in females
The mean values of buccolingual and mesiodistal dimensions of males and females were calculated. The data obtained were subjected to the statistical analysis with the Microsoft Excel, using descriptive statistics. The unpaired $t$-test was applied to compare the dimensions measured for males and females. $p \leq 0.05$ was considered statistically significant.

The mean values of buccolingual and mesiodistal dimensions of males and females were subjected to the formula to calculate sexual dimorphism.

Sexual dimorphism (in percentage) $=\mathrm{Xm} / \mathrm{Xf}-1 \times 100$

$\mathrm{Xm}=$ mean value for males; $\mathrm{Xf}=$ mean value for females

\section{Results and Observations}

When comparison between right and left buccolingual width of intraoral and cast in female, right buccolingual width intraoral (10.33 $\pm 0.90)$, cast $(10.43 \pm 0.92)$ and left buccolingual width intraoral $(10.15 \pm 0.91)$, cast $(10.25 \pm 0.89)$. $p$ value $>0.05$, so there was no significance as shown in Table 1 and Figure 1.

When comparison between right and left mesiodistal width of intraoral and cast in female, right mesiodistal width intraoral $(9.61 \pm$ $0.73)$, cast $(9.70 \pm 0.77)$ and left mesiodistal width intraoral $(9.65 \pm$ 0.79 ), cast $(9.75 \pm 0.80)$. $p$ value $>0.05$, so there was no significance as shown in Table 2 and Figure 2.

When comparison between right and left buccolingual width of intraoral and cast in male, right buccolingual width intraoral (10.86 $\pm 0.46)$, cast $(10.97 \pm 0.58)$ and left buccolingual width intraoral $(10.63 \pm 0.49)$, cast $(10.73 \pm 0.52)$. Intraoral $p$ value $<0.05$, so there was significance intraoral as shown in Table 3 and Figure 3.

When comparison between right and left mesiodistal width of intraoral and cast in female, right mesiodistal width intraoral $(9.87 \pm$ $0.63)$, cast $(9.97 \pm 0.63)$ and left mesiodistal width intraoral $(9.73 \pm$ $0.51)$, cast $(9.80 \pm 0.55) . p$ value $>0.05$, so there was no significance as shown in Table 4 and Figure 4.

Table 2: Mean \pm SD of right and left mesiodistal width of intraoral and cast in female

\begin{tabular}{|c|c|c|c|c|}
\hline \multirow[b]{2}{*}{ Parameters } & \multicolumn{2}{|c|}{ Mean $\pm S D$} & \multirow[b]{2}{*}{$p$ value } & \multirow[b]{2}{*}{ Significance } \\
\hline & Right & Left & & \\
\hline Intraoral & $9.61 \pm 0.73$ & $9.65 \pm 0.79$ & 0.8147 & Nonsignificant \\
\hline Cast & $9.70 \pm 0.77$ & $9.75 \pm 0.80$ & 0.7766 & Nonsignificant \\
\hline
\end{tabular}

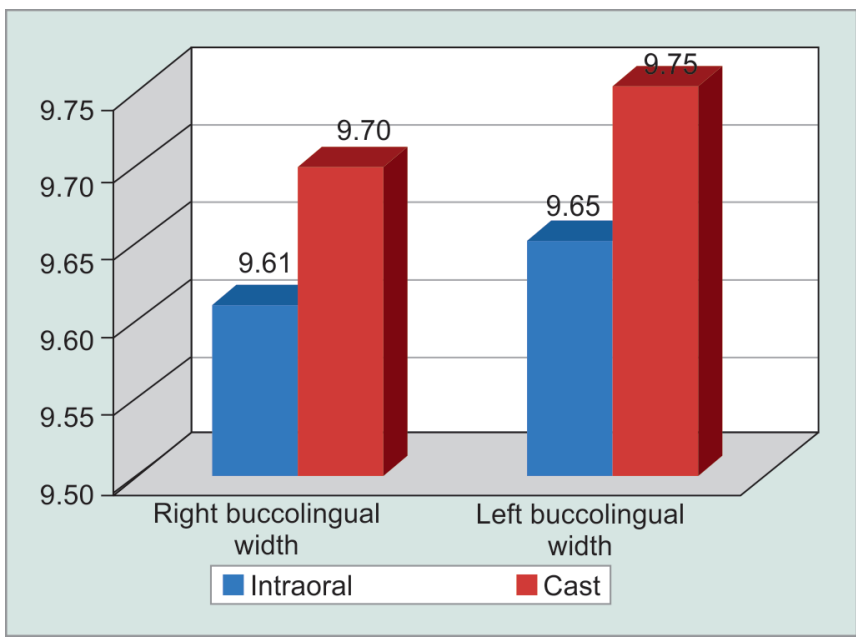

Fig. 2: Mean \pm SD of right and left mesiodistal width of intraoral and cast in female 
Table 3: Mean \pm SD of right and left buccolingual width of intraoral and cast in male

\begin{tabular}{|c|c|c|c|c|}
\hline \multirow[b]{2}{*}{ Parameters } & \multicolumn{2}{|c|}{ Mean $\pm S D$} & \multirow[b]{2}{*}{$p$ value } & \multirow[b]{2}{*}{ Significance } \\
\hline & Right & Left & & \\
\hline Intraoral & $10.86 \pm 0.46$ & $10.63 \pm 0.49$ & 0.0335 & Significant \\
\hline Cast & $10.97 \pm 0.58$ & $10.73 \pm 0.52$ & 0.0549 & Nonsignificant \\
\hline
\end{tabular}

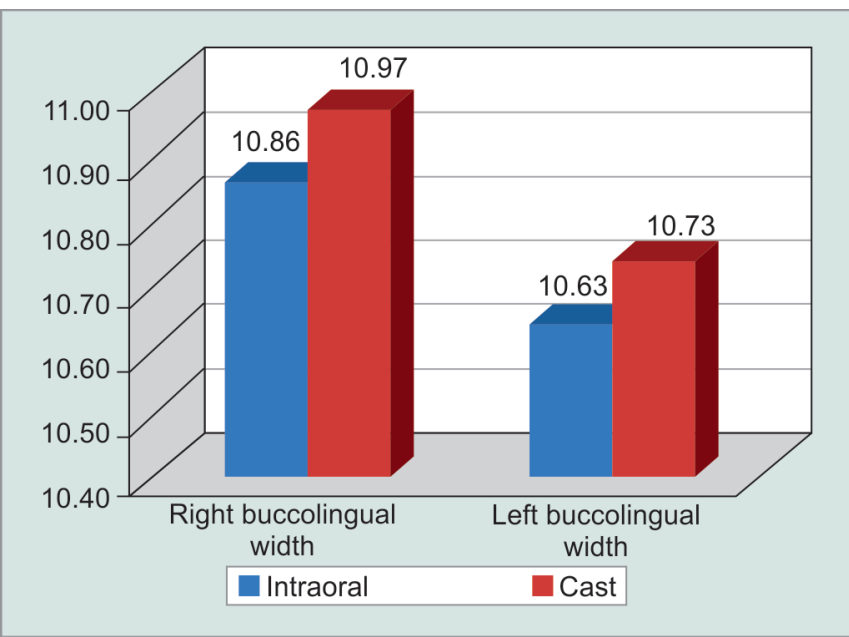

Fig. 3: Mean \pm SD of right and left buccolingual width of intraoral and cast in male

Table 5: Mean \pm SD of right buccolingual width of intraoral and cast according to sex

\begin{tabular}{|c|c|c|c|c|}
\hline \multirow[b]{2}{*}{ Parameters } & \multicolumn{2}{|c|}{ Mean $\pm S D$} & \multirow[b]{2}{*}{$p$ value } & \multirow[b]{2}{*}{ Significance } \\
\hline & Male & Female & & \\
\hline Intraoral & $10.86 \pm 0.46$ & $10.33 \pm 0.90$ & 0.0014 & Very significant \\
\hline Cast & $10.97 \pm 0.58$ & $10.43 \pm 0.92$ & 0.0024 & Very significant \\
\hline
\end{tabular}

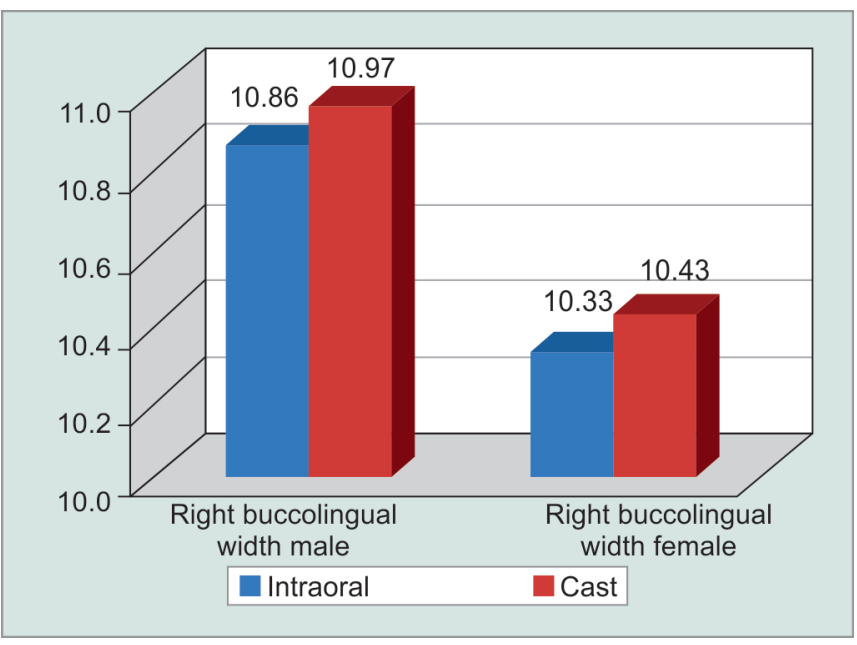

Fig. 5: Mean \pm SD of right buccolingual width of intraoral and cast according to sex

When comparison between male and female right buccolingual width intraoral and cast, in male right buccolingual width intraoral $(10.86 \pm 0.46)$, cast $(10.97 \pm 0.58)$ and in female intraoral (10.33 $\pm 0.90)$, cast $(10.43 \pm 0.92)$. $p$ value $<0.005$, so there was very significance as shown in Table 5 and Figure 5.
Table 4: Mean \pm SD of right and left mesiodistal width of intraoral and cast in male

\begin{tabular}{|c|c|c|c|c|}
\hline \multirow[b]{2}{*}{ Parameters } & \multicolumn{2}{|c|}{ Mean $\pm S D$} & \multirow[b]{2}{*}{$p$ value } & \multirow[b]{2}{*}{ Significance } \\
\hline & Right & Left & & \\
\hline Intraoral & $9.87 \pm 0.63$ & $9.73 \pm 0.51$ & 0.2780 & Nonsignificant \\
\hline Cast & $9.97 \pm 0.63$ & $9.80 \pm 0.55$ & 0.2024 & Nonsignificant \\
\hline
\end{tabular}

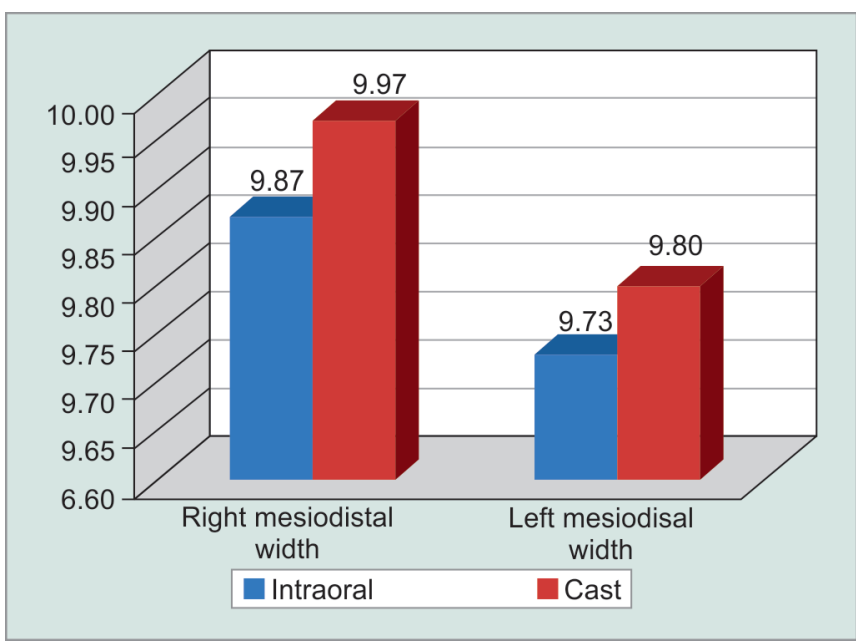

Fig. 4: Mean \pm SD of right and left mesiodistal width of intraoral and cast in male

Table 6: Mean \pm SD of left buccolingual width of intraoral and cast according to sex

\begin{tabular}{|c|c|c|c|c|}
\hline \multirow[b]{2}{*}{ Parameters } & \multicolumn{2}{|c|}{ Mean $\pm S D$} & \multirow[b]{2}{*}{$p$ value } & \multirow[b]{2}{*}{ Significance } \\
\hline & Male & Female & & \\
\hline Intraoral & $10.63 \pm 0.49$ & $10.15 \pm 0.91$ & 0.0044 & Very significant \\
\hline Cast & $10.73 \pm 0.52$ & $10.25 \pm 0.89$ & 0.0043 & Very significant \\
\hline
\end{tabular}

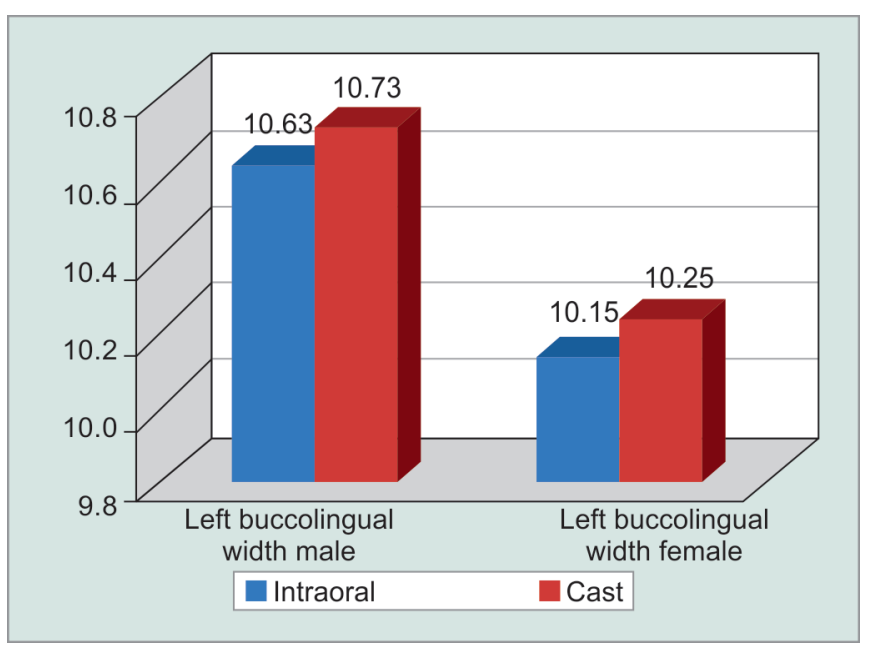

Fig. 6: Mean $\pm S D$ of left buccolingual width of intraoral and cast according to sex

When comparison between male and female left buccolingual width intraoral and cast, in male left buccolingual width intraoral $(10.63 \pm 0.49)$, cast $(10.73 \pm 0.52)$ and in female intraoral $(10.15 \pm 0.91)$, cast $(10.25 \pm 0.89)$. $p$ value $<0.005$, so there was very significance as shown in Table 6 and Figure 6. 
Table 7: Mean \pm SD of right mesiodistal width of intraoral and cast according to sex

\begin{tabular}{|c|c|c|c|c|}
\hline \multirow[b]{2}{*}{ Parameters } & \multicolumn{2}{|c|}{ Mean $\pm S D$} & \multirow[b]{2}{*}{$p$ value } & \multirow[b]{2}{*}{ Significance } \\
\hline & Male & Female & & \\
\hline Intraoral & $9.87 \pm 0.63$ & $9.61 \pm 0.73$ & 0.0921 & Nonsignificant \\
\hline Cast & $9.97 \pm 0.63$ & $9.70 \pm 0.77$ & 0.0901 & Nonsignificant \\
\hline
\end{tabular}

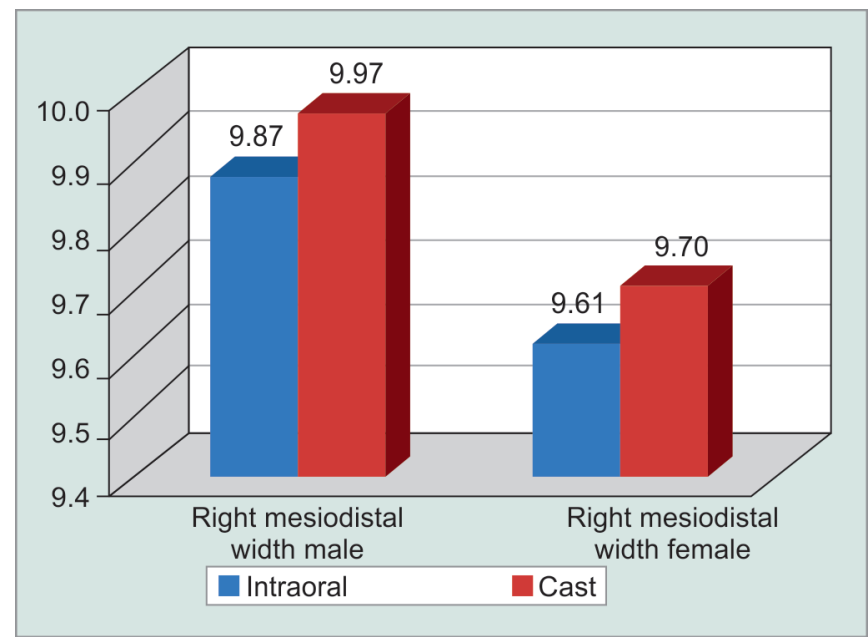

Fig. 7: Mean \pm SD of right mesiodistal width of intraoral and cast according to sex

When comparison between male and female right mesiodistal width intraoral and cast, in male right mesiodistal width intraoral $(9.87 \pm 0.63)$, cast $(9.97 \pm 0.63)$ and in female intraoral $(9.61 \pm 0.73)$, cast $(9.70 \pm 0.77)$. $p$ value $>0.05$, so there was nonsignificance as shown in Table 7 and Figure 7.

When comparison between male and female left mesiodistal width intraoral and cast, in male left mesiodistal width intraoral $(9.73 \pm 0.51)$, cast $(9.80 \pm 0.55)$ and in female intraoral $(9.65 \pm 0.79)$, cast $(9.75 \pm 0.80)$. $p$ value $>0.05$, so there was nonsignificance as shown in Table 8 and Figure 8.

The sexual dimorphism was slightly greater on the right side than the left side. Buccolingual width of right maxillary molar teeth shows maximum sexual dimorphism (intraoral 5.13\%, cast 5.18\%) among all measurements as shown in Table 9.

\section{Discussion}

The present study established the morphometric difference of maxillary first molars in both males and females and its role in gender estimation. Mesiodistal and buccolingual diameters of right and left maxillary first molars in males and females were measured both intraorally and on study casts.

The present study showed bilateral symmetry of the maxillary permanent first molar as no significant difference was found in the dimensions of the maxillary right and left permanent first molar in both males and females, indicating almost symmetric dimensions. This finding is in agreement with most of the studies done by Preeti et al., ${ }^{9}$ Rai et al., ${ }^{10}$ and Garn et al., ${ }^{11}$ which showed no tendency for the mesiodistal as well as buccolingual crown dimensions on one side to be consistently larger than on the other side.

The present study established the sexual dimorphism on the morphometry of maxillary first molars. Buccolingual and mesiodistal diameters of right and left maxillary first molars in
Table 8: Mean \pm SD of left mesiodistal width of intraoral and cast according to sex

\begin{tabular}{|c|c|c|c|c|}
\hline \multirow[b]{2}{*}{ Parameters } & \multicolumn{2}{|c|}{ Mean $\pm S D$} & \multirow[b]{2}{*}{$p$ value } & \multirow[b]{2}{*}{ Significance } \\
\hline & Male & Female & & \\
\hline Intraoral & $9.73 \pm 0.51$ & $9.65 \pm 0.79$ & 0.5921 & Nonsignificant \\
\hline Cast & $9.80 \pm 0.55$ & $9.75 \pm 0.80$ & 0.7455 & Nonsignificant \\
\hline
\end{tabular}

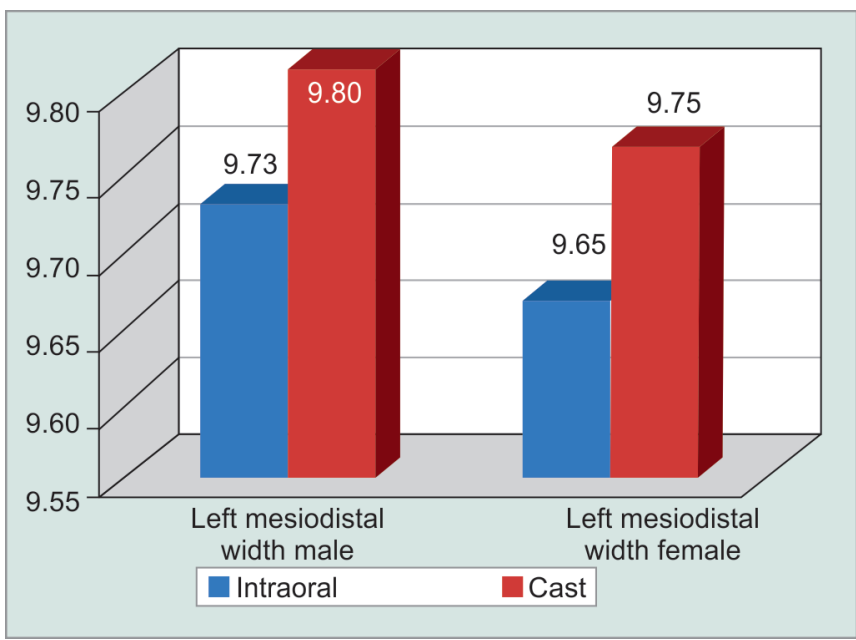

Fig. 8: Mean \pm SD of left mesiodistal width of intraoral and cast according to sex

Table 9: Sexual dimorphism (in percentage) of maxillary molar teeth

\begin{tabular}{lll}
\hline Parameters & Intraoral (\%) & Cast (\%) \\
\hline Right mesiodistal width & 2.71 & 2.78 \\
Left mesiodistal width & 0.83 & 0.51 \\
Right buccolingual width & 5.13 & 5.18 \\
Left buccolingual width & 4.73 & 4.68 \\
\hline
\end{tabular}

males and females were measured both intraorally and on study casts. The comparison of mean values of parameters measured between males and females showed highly statistically significant differences with $p<0.001$ and these results were in agreement with the studies done by Perzigian et al., ${ }^{12}$ Ghose et al., ${ }^{13}$ Stroud et al., ${ }^{14}$ Hattab et al., ${ }^{15}$ Rai et al., ${ }^{16}$ and Ghodosi et al. ${ }^{17}$ in which they have observed that the males had larger teeth than females in all the dimensions. Such differences in dimensions of the teeth can be due to greater dentine thickness in males as compared to females, as the $\mathrm{Y}$ chromosome increases the mitotic potential of the tooth germ and induces dentinogenesis; while the $X$ chromosome induces amelogenesis. ${ }^{18}$

In the intraoral group, the right maxillary first molar was found to exhibit the greatest sexual dimorphism (5.13\%) in terms of buccolingual dimension. The results of the present study were in agreement with the study done by Rai et al., ${ }^{16}$ who found a similar result with the right maxillary first molar exhibiting the greatest sexual dimorphism (8.9\%). In the study cast group, the right maxillary first molar was found to exhibit the greatest sexual dimorphism (5.18\%) in terms of buccolingual dimension while the least dimorphic value was that for the left maxillary first molar $(0.51 \%)$ in terms of mesiodistal dimensions.

Comparing the properties of mesiodistal dimension with buccolingual dimension, it was observed in this study that the mean 
buccolingual dimension on the right and left sides in both genders were larger than the mesiodistal dimension on the corresponding sides. The buccolingual dimensions of maxillary first molars in the present study were found to exhibit greater sexual dimorphism than mesiodistal dimensions of the same teeth. The results of this study are in agreement with the study done by Garn et al. ${ }^{11}$ who found that among 117 adolescents, sexual dimorphism amounted to $5.6 \%$ for the buccolingual diameter as compared to $4.2 \%$ for the mesiodistal diameter of the same teeth.

Iscan and Kedici ${ }^{19}$ stated that an advantage of buccolingual dimension is that it is more reliably measured than others, while this is true for posterior teeth. The major disadvantage of mesiodistal measurements is that they are more difficult to obtain than buccolingual measurements considering the proximal contact that exists between teeth.

\section{ConcLusion}

The buccolingual dimensions in the present study were found to exhibit greater sexual dimorphism than mesiodistal dimensions of permanent maxillary first molars. Thus, this study indicates that maxillary first molar shows significant sexual dimorphism and can be used as an adjunct along with other accepted procedures for sex estimation.

\section{References}

1. Shireen A, Ara SA, Azzeghaiby SN, et al. Sex determination potential from canine tooth dimensions. British J Medic Med Res 2014;4(32):5133-5143. DOI: 10.9734/BJMMR/2014/11005.

2. More C, Patel P, Peter R. Analysis of Palatal Rugae pattern in Indian and Nepalese population - a comparative study. J Oral Med, Oral Surg, Oral Pathol Oral Radiol 2015;1(3):108-113.

3. More C, Patil R, Asrani M, et al. Cheiloscopy-A Review. Indian J Foren Med Toxicol 2009;3(1):17-20.

4. Dharman S, Gnanasundaram N, Gopal M, et al. Phenotypic differences in teeth dimensions among Chennai population: An aid in sex determination. J Indian Acad Oral Med Radiol 2015;27(2):171-177.
5. Mirza FH, Siddiqui MM, Memon AA, et al. Gender determination using canine mandibular index, a new perspective in forensic odontology. MC Supplement 2012(Suppl):52-54.

6. Kaushal S, Patnaik VVG, Agnihotri G. Mandibular canines in sex determination. J Anat Soc India 2003;52(2):119-124.

7. Aggarwal B, Vasudeva K, Kaushal S, et al. Gender based comparison of intercanine distance of mandibular permanent canine in different populations. JPAFMAT 2008;8(2):6-9.

8. Filipovic G, Kanjevac T, Cetenovic B, et al. Sexual dimorphism in the dimensions of teeth in Serbian population. Coll Antropol 2016;40(1):23-28.

9. Preeti N, Balaji Rao B, Anniger RG. A study of tooth size, symmetry and sexual dimorphism. JFMT 1999;16:10-13.

10. Rai B, Jain R, Duhan J, et al. Importance of maxillary first molar for sex determination. Internet J Dent Sci 2007;4:2.

11. Garn SM, Lewis AB, Kerewsky RS. Sexual dimorphism in the buccolingual tooth diameter. J Dent Res 1966;45(6):1819. DOI: $10.1177 / 00220345660450064301$.

12. Perzigian AJ. The dentition of the Indian Knoll skeletal population: odontometrics and cup number. Am J Phys Anthropol 1976;44(1):113121. DOI: 10.1002/ajpa.1330440116.

13. Ghose LJ, Baghdady V. Analysis of the Iraqi dentition: Mesiodistal crown diameters of permanent teeth. J Dent Res 1979;58(3):10471054. DOI: $10.1177 / 00220345790580030301$.

14. Stroud JL, Buschang PH, Goaz PW. Sexual dimorphism in mesiodistal dentin and enamel thickness. Dentomaxillofac Radiol 1994;23(3):169171. DOI: 10.1259/dmfr.23.3.7835519.

15. Hattab FN, al-Khateeb S, Sultan I. Mesiodistal crown diameters of permanent teeth in Jordanians. Arch Oral Biol 1996;41(7):641-645. DOI: 10.1016/S0003-9969(96)00066-0.

16. Rai B, Dhattarwal SK, Anand SC. Sex determination from tooth Medico-legal update 2008;8(1):3-5.

17. Ghodosi A, Mosharraf R, Nia FF. Sexual variation in bucco-lingual dimensions in Iranian dentition. Inter J Dental Anthropol 2008;12:1-7.

18. Vodanovic M, Demo Z, Njemirovskij V, et al. Odontometrics: a useful method for sex determination in an archaeological skeletal population? J Archaeolog Sci 2007;34(6):905-913. DOI: 10.1016/j. jas.2006.09.004.

19. Iscan MY, Kedici PS. Sexual variation in bucco-lingual dimensions in Turkish dentition. Forensic Sci Int 2003;137(2-3):160-164. DOI: 10.1016/ S0379-0738(03)00349-9. 